\title{
LAND COVER MAPPING USING A NOVEL COMBINATION MODEL OF SATELLITE IMAGERIES: CASE STUDY OF A PART OF THE CAMERON HIGHLANDS, PAHANG, MALAYSIA
}

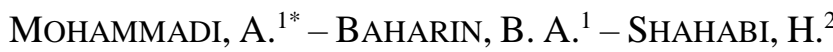 \\ ${ }^{I}$ Faculty of Built Environment and Surveying, Universiti Teknologi Malaysia (UTM) \\ 81310 Johor Bahru, Malaysia \\ (e-mail: baharinahmad60@gmail.com) \\ ${ }^{2}$ Department of Geomorphology, Faculty of Natural Resources, University of Kurdistan \\ Sanandaj, Iran \\ (e-mail: himanshahabi@gmail.com) \\ *Corresponding author \\ e-mail: ayubmohammadi1990@gmail.com \\ (Received $19^{\text {th }}$ Oct 2018; accepted $22^{\text {nd }}$ Dec 2018)
}

\begin{abstract}
Information about land covers is essential for a variety of purposes, such as environmental studies, sustainable development, and regional managements. This study aims to use a novel combination model to generate a land cover map in a part of the Cameron Highlands, Malaysia, where there are different kind of land covers, including tea plantation, florification and forest. Because of the high similarity in land covers of the study area, only through satellite imageries with a high spatial and spectral resolution the land covers can be differentiated. We have combined satellite imageries of Sentinel-1 (S1A, GRD, IW) and Landsat-8 (Operational land imager) for the year 2017 as well as different algorithms of Maximum Likelihood (ML), Minimum Distance (MD), Support Vector Machine (SVM), Spectral Angle Mapper (SAM) and Artificial Neural Network (ANN). The results showed that the combination model is an applicable technique for extracting land covers in areas with high similarities in land covers. The overall accuracy of the confusion matrix and the Kappa Coefficient are $98.1984 \%$ and 0.9579 , respectively, which indicate that it is a robust model for extracting land covers in areas like the Cameron Highlands. The obtained results can be useful for different purposes, including urban and environmental management, change detection, agriculture and many more purposes.
\end{abstract}

Keywords: land use, satellite data, remote sensing, geographic information system, Cameron Highlands

\section{Introduction}

Information about Land Covers (LC) and changes affecting them is essential for many purposes, including urban planning, vegetation and environmental issues (Shahabi et al., 2012; Chen et al., 2015; Gómez et al., 2016). Combination model refers to the ability of using two or more satellite imageries, in which we can improve the spectral resolution to detect the land covers more precisely. In recent years, database and methodology for creating a land cover map have undergone considerable changes (Tehrany et al., 2014; Megahed et al., 2015). Advancements in Remote Sensing (RS) technology and also a demand for using them for different issues have made it a the most used technology for gaining information about earth surface objects since 2 decades ago (Walker and Blaschke, 2008; Belward and Skøien, 2015; Ma et al., 2017).

Land cover has been undergoing considerable changes in either local or global scales (Megahed et al., 2015; Miettinen et al., 2016). Land cover mapping is not an easy issue and needs considerable attention regarding both data collection and model selection (Megahed et al., 2015; Khatami et al., 2016). Selecting data sets should be based on the 
study area and the kinds, shapes and color of the land covers, which help us to select appropriate satellite imagery (Moser et al., 2013; Tehrany et al., 2014; Hasmadi et al., 2017). Since the study area is one of the touristic destinations for both locals and foreigners, so its preservation for Malaysian government is vital.

One of the highlighted issues when generating a land cover map from satellite imagery is the spectral and the spatial resolutions (Griffiths et al., 2013; Poursanidis et al., 2015). However, the precise information about land cover is highly essential. Until about 15 years ago land cover data bases were in form of pre-existing maps, gathered from field survey and previous maps (Griffiths et al., 2013). From two decades ago onwards, RS and Geographical Information System (GIS) have drawn researcher's attention toward using satellite imagery and machine learning algorithms (Loveland et al., 2000; Tehrany et al., 2014).

Many studies have been conducted with the land cover mapping using different models, techniques and satellite imageries, including global land cover map using Landsat satellite imageries and SVM algorithm (Gong et al., 2013); object-based and pixel-based approaches using SPOT-5 satellite imagery (Tehrany et al., 2014); airborne LiDAR data (Yan et al., 2015); different algorithms of Savitzky-Golay, asymmetric Gaussian, double-logistic, Whittaker smoother and discrete Fourier using MODIS imagery for Great Lake, USA (Shao et al., 2016); supervised and unsupervised algorithms using SPOT-5 satellite imagery (Hasmadi et al., 2017); hyperion data using SVMs classifier (Lamine et al., 2018).

The main objective of the current study was to use a novel combination model for extracting land covers in a part of the Cameron Highlands, Pahang, Malaysia. However, this study dealt with two significant combinations of satellite imageries (Landsat- 8 and Sentinel-1), and also combination of different algorithms of ML, MD, SVM, SAM, and ANN by using a Decision Tree (DT) model.

\section{Materials and methods}

\section{Description of the study area}

The study area is a part of the Cameron Highlands, Pahang, Malaysia between longitudes $101^{\circ} 20^{\prime} 00^{\prime \prime} \mathrm{E}$ to $101^{\circ} 27^{\prime} 10^{\prime \prime} \mathrm{E}$ and latitudes $4^{\circ} 23^{\prime} 30^{\prime \prime} \mathrm{N}$ to $4^{\circ} 31^{\prime} 10^{\prime \prime} \mathrm{N}$ (Fig. 1). This scope with an area of $81.249 \mathrm{~km}^{2}$ is located approximately in the southwestern part of the Cameron Highlands (Tien Bui et al., 2018). The lowest and the highest area of the study area is 912 and $1960 \mathrm{~m}$ above the sea level, respectively. However, the average rainfall fluctuates between $1800 \mathrm{~mm}$ to $3000 \mathrm{~mm}$ annually (Jebur et al., 2015; Tien Bui et al., 2018).

\section{Data collection}

Sentinel-1 is a part of the Copernicus Programme conducted by the European Space Agency (ESA). This product consists of the two satellite platforms of 1A and 1B. It has four sensor modes (Strip Map (SM), Interferometric Wide Swath (IW), Wave (WV), and Extra Wide Swath (EW)), and three product types namely, Ground Range Detected (GRD), Single Look Complex (SLC), and Ocean (OCN) (Potin et al., 2012). In this research, we have acquired Landsat- 8 and Sentinel-1 satellite imageries for the year 2017 online for free from www.earthexplorer.usgs.gov and www.scihub.copernicus.eu, 
respectively. Table 1 and Figure 2 illustrate the technical characteristics of satellite data and geographical position of the study area on the satellite imageries, respectively.

\section{Research methodology}

Using Sentinel Application Platform (SNAP) software and Environment for Visualizing Image (ENVI) software, either images radiometrically, spectrally and geometrically were corrected, co-registered and stacked. Using pan-sharpening command in ENVI software, the spatial resolution of Landsat- 8 improved to $15 \mathrm{~m}$ by its panchromatic band, then via co-registration process the spatial resolution of Landsat-8 (Slave image) enhanced to $10 \mathrm{~m}$ by Sentinel-1 as the master image.

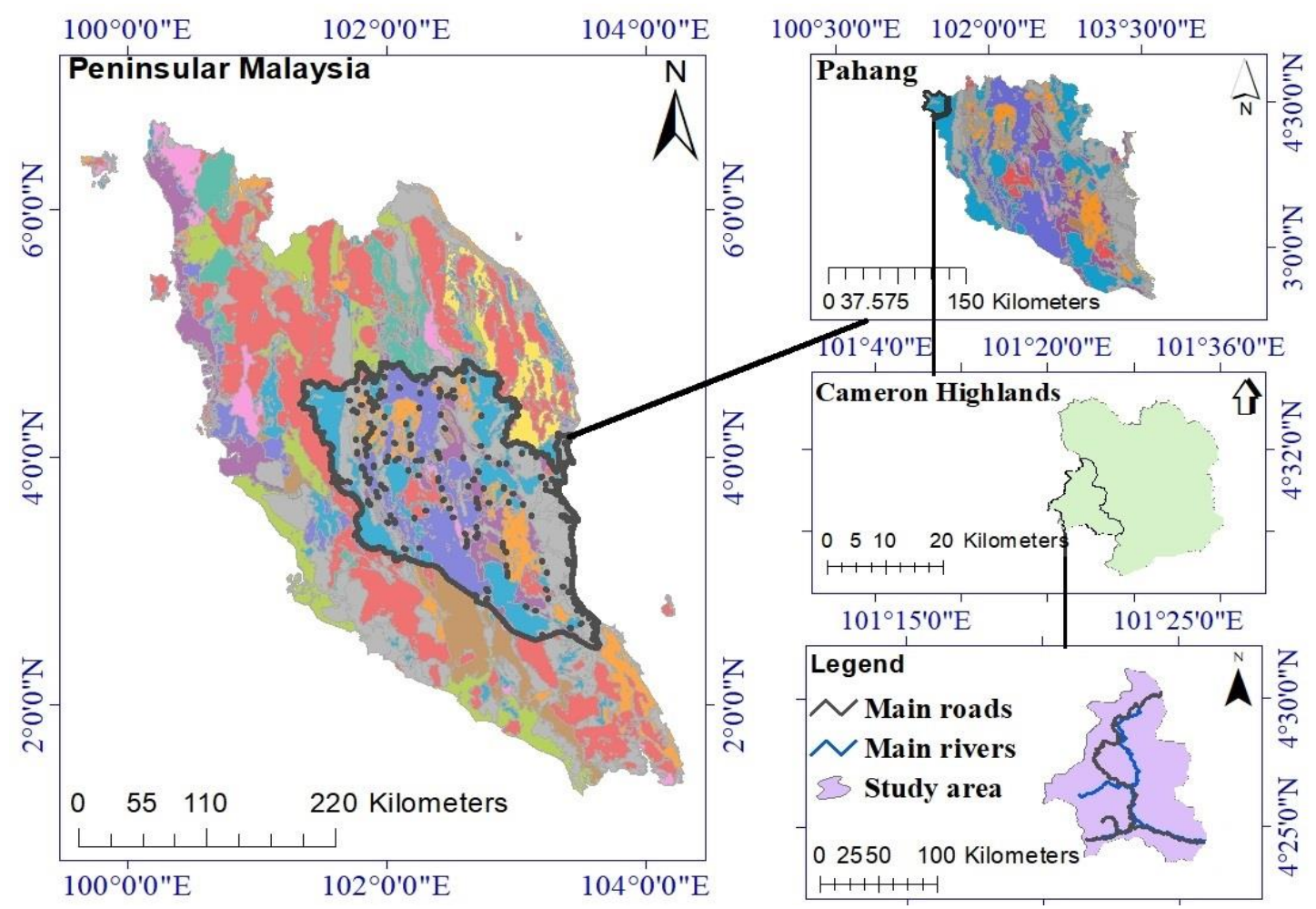

Figure 1. Geographical position of the study area

Table 1. Show the technical attributes of Landsat-8 and Sentinel-1

\begin{tabular}{c|c|c}
\hline No. & Sentinel-1 & Landsat-8 \\
\hline Sensor & Synthetic Aperture Radar (SAR) & Operational Land Imager (OLI) \\
\hline Spatial resolution & $10 \mathrm{~m}$ & $-30 \mathrm{~m}$ (Multispectral) \\
$-15 \mathrm{~m}$ (Panchromatic)
\end{tabular}




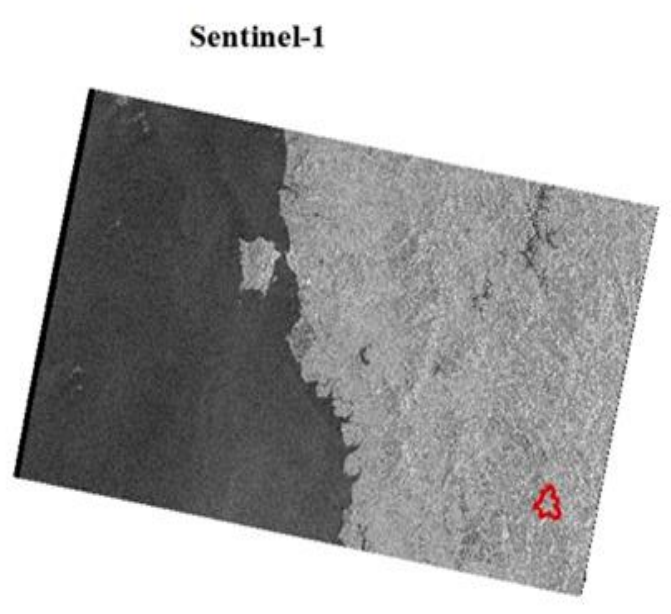

$\sum$ Study area

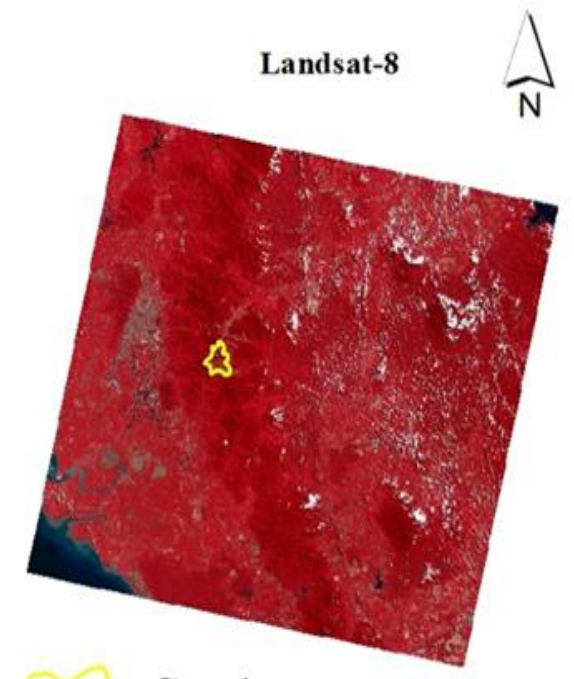

Study area

Figure 2. Shows scope of the study on the satellite data

After picking up the Region of Interests (ROIs) from co-registered image, different algorithms of maximum likelihood, minimum distance, support vector machine, spectral angle mapper and artificial neural network, were applied for classification. Each algorithm has shown a 1 or 2 land covers better, therefore in order to use the information of all algorithms, the DT method was used. Finally, after the post classification process, to evaluate the overall accuracy some Ground Control Points (GCPs) were extracted using Google Earth (For water body) and field checks for the other land covers (Fig. 3). Using ArcGIS the raster map was converted into a vector file and then was dissolved as the number of land covers. Moreover, after calculating the area for each land cover, the attribute table was imported into Microsoft Excel for calculating the total area and creating the final output table.

\section{Description of the used algorithms}

\section{Maximum likelihood (ML)}

Maximum likelihood model assumes that the statistics for each class are normally distributed and measures the probability that a given-pixel belongs to a certain class (Stamatakis, 2006). Each pixel is assigned to a class, which has the highest probability (Richards and Richards, 1999; Stamatakis, 2006). Once the highest probability has been smaller than the threshold, then the pixel remained unclassified (Richards and Richards, 1999).

\section{Minimum distance $(M D)$}

The minimum distance classification utilize the mean vector of every endmember and measures the Euclidean distance from unknown pixels to the mean vector for each class (Abtan et al., 2017; Kolesár, 2018). Based on the specified standard deviation, number of classes and a distance threshold, all pixels will be classified to the nearest class, however, some pixels may remain unclassified if they do not meet the selected criteria. 


$$
-1839-
$$

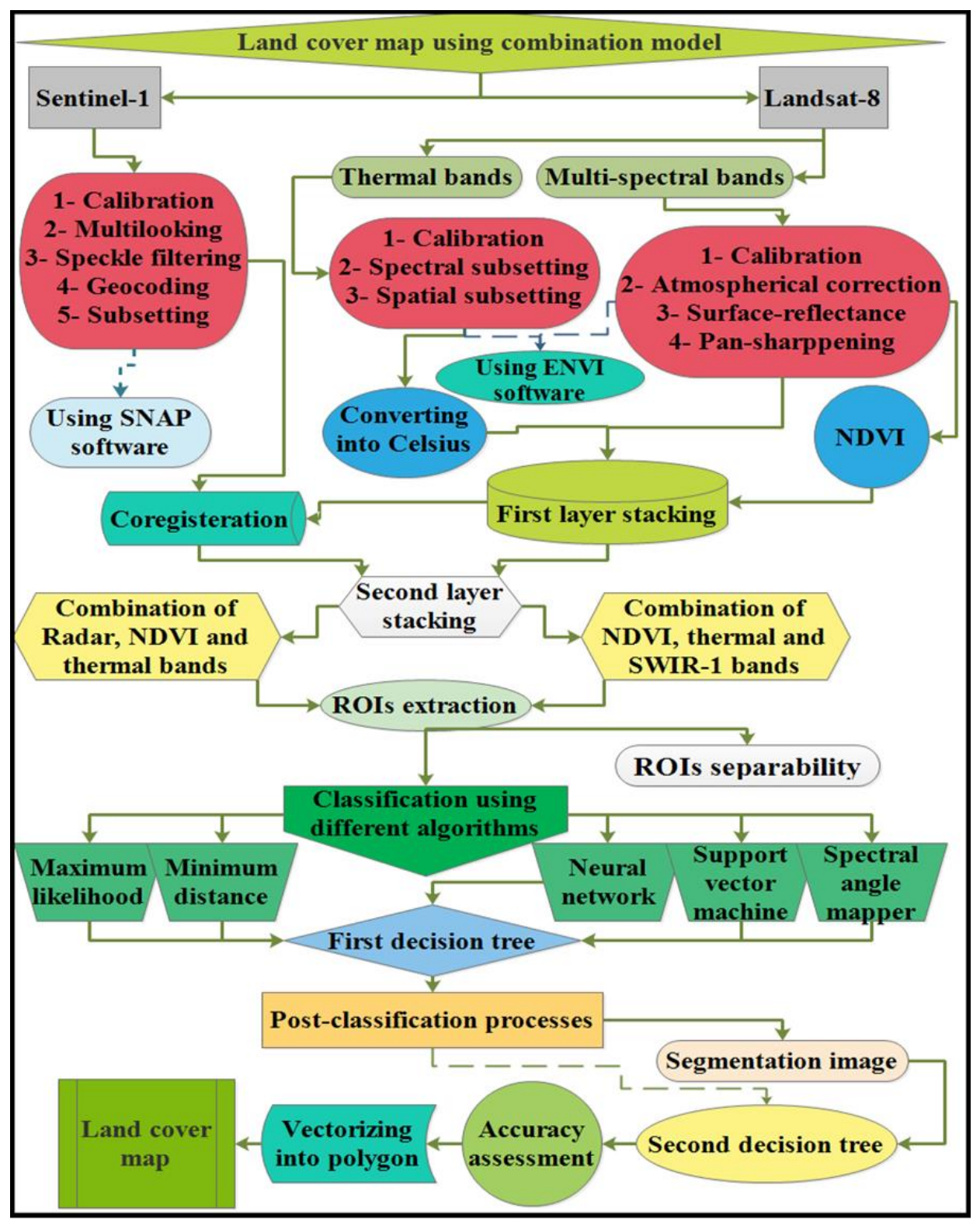

Figure 3. Methodology of the study

\section{Neural network (NN)}

The neural network technique implies standard back-propagation for a supervised learning (Yoshida and Omatu, 1994). You can choose a number of hidden layers to use and also you can select between hyperbolic or logistic activation functions (Zhang and Foody, 2001). The NN algorithm can be used to perform non-linear classification (Scott et al., 2017). In this model, the error is back-propagated through the network and weight adjustment is made by using a recursive method (Scott et al., 2017; Chakraborty and Roy, 2018).

\section{Support vector machine (SVM)}

The SVM is a fast and accurate model for the land cover/ land use studies (Sukawattanavijit et al., 2017). This model provides a good result from noisy and 
complex data ( $\mathrm{Gu}$ and Sheng, 2017). It tries to separate the created classes with a decision surface, which maximizes the margin between the selected classes (Mohammadi et al., 2018). Despite this fact that the SVM is a binary classifier, it works as a multiclass classifier as well, provided that several binary SVM classifiers are combined ( $\mathrm{Gu}$ and Sheng, 2017; Mohammadi et al., 2018). The classifier performs training at a lower resolution level, because retraining at each level provides higher accuracy for the resampled image, however, it considers the rule image values to identify those that exceed the probability threshold (Sukawattanavijit et al., 2017; Mohammadi et al., 2018).

\section{Spectral angle mapper (SAM)}

The SAM classifier is a physically-based classification that utilize an n-D angle to match pixels to reference spectra (Renza et al., 2017). The model determines the spectral similarity between two different spectra by calculating the angle among the spectra (Kumar et al., 2015). End-member spectra used by SAM model can come from ASCII files, spectral libraries, and you can extract them from Region of Interests (ROIs) (Renza et al., 2017; Yan and Roy, 2018). SAM compares the angles between the endmember spectrum vector and each pixel vector in n-D space (Yan and Roy, 2018). However, smaller angles represent a closer match to the reference spectrum.

\section{Decision tree $(D T)$}

A DT is a type of multistage classifier, which can be applied to a single imagery or a stack of images (Chasmer et al., 2014). It comprises of a series of binary decisions, which are applied to determine the correct group for each pixel (Hua et al., 2017). It can be based on the available characteristics of the dataset (Lu et al., 2014). As an example, you may have an elevation dataset and two multispectral imageries that collected at different times, and any of those images can contribute to decision within the same tree.

\section{Validation}

The confusion matrix is important to validate statistical classification (Stehman, 1997). Overall accuracy is calculated by measuring the number of corrected classified pixels then dividing them by the total number of pixels (Eq. 1) (Jensen and Lulla, 1987). Kappa coefficient is measured through multiplying the total pixel classes by the sum of the confusion matrix, then subtracting the sum of ground truth pixels in a class times the sum of classified pixels in that class summed over all classes (Eq. 2).

$$
O A=\frac{1}{N} \sum P_{\text {ii }}
$$

where: $\mathrm{OA}=$ total accuracy, $\mathrm{N}=$ total number of test pixels, and $\sum P_{i i}=$ total pixels that are correctly classified.

Equation for the Kappa coefficient is written as below:

$$
K=\left(O A-\frac{1}{q}\right)\left(1-\frac{1}{q}\right)
$$

where: $\mathrm{K}=$ kappa coefficient and $\mathrm{q}=$ unclassified pixels. 


\section{Results and discussion}

One of the most important steps in extracting ROIs is the separability assessment of them (Laurin et al., 2013; Megahed et al., 2015; Levin, 2016). However, the value for measuring the ROIs separability is between 1 and 2, the values less than 1.8 are not acceptable (Laurin et al., 2013). The higher the value the more precise the ROIs are (Levin, 2016). Table 2 illustrates the least to most separability values of extracted ROIs for this study.

Table 2. Pair separation of ROIs (least to most)

\begin{tabular}{c|c}
\hline Vegetation/florification and township $=1.99$ & Water body and cleared forest $=1.99$ \\
\hline Vegetation/florification and tea plantation $=1.99$ & Township and tea plantation $=1.99$ \\
\hline Road network \& vegetation/florification $=1.99$ & Cleared forest \& vegetation/florification $=2$ \\
\hline Road network and township $=1.99$ & Forest and water body $=2$ \\
\hline Forest and township $=1.99$ & Forest and road network $=2$ \\
\hline Cleared forest and township $=1.99$ & Forest and cleared forest $=2$ \\
\hline Water body and township $=1.99$ & Water body and tea plantation $=2$ \\
\hline Water body and road network $=1.99$ & Cleared forest and tea plantation $=2$ \\
\hline Forest and vegetation/florification $=1.99$ & Forest and tea plantation $=2$ \\
\hline Water body \& vegetation/florification $=1.99$ & Cleared forest and road network $=2$ \\
\hline
\end{tabular}

It is worth mentioning that the pair separation of the extracted ROIs from the combination of Sentinel-1 and Landsat- 8 satellite imageries showed that this model is a robust way in extracting ROIs for generating land cover maps (Fig. 4).

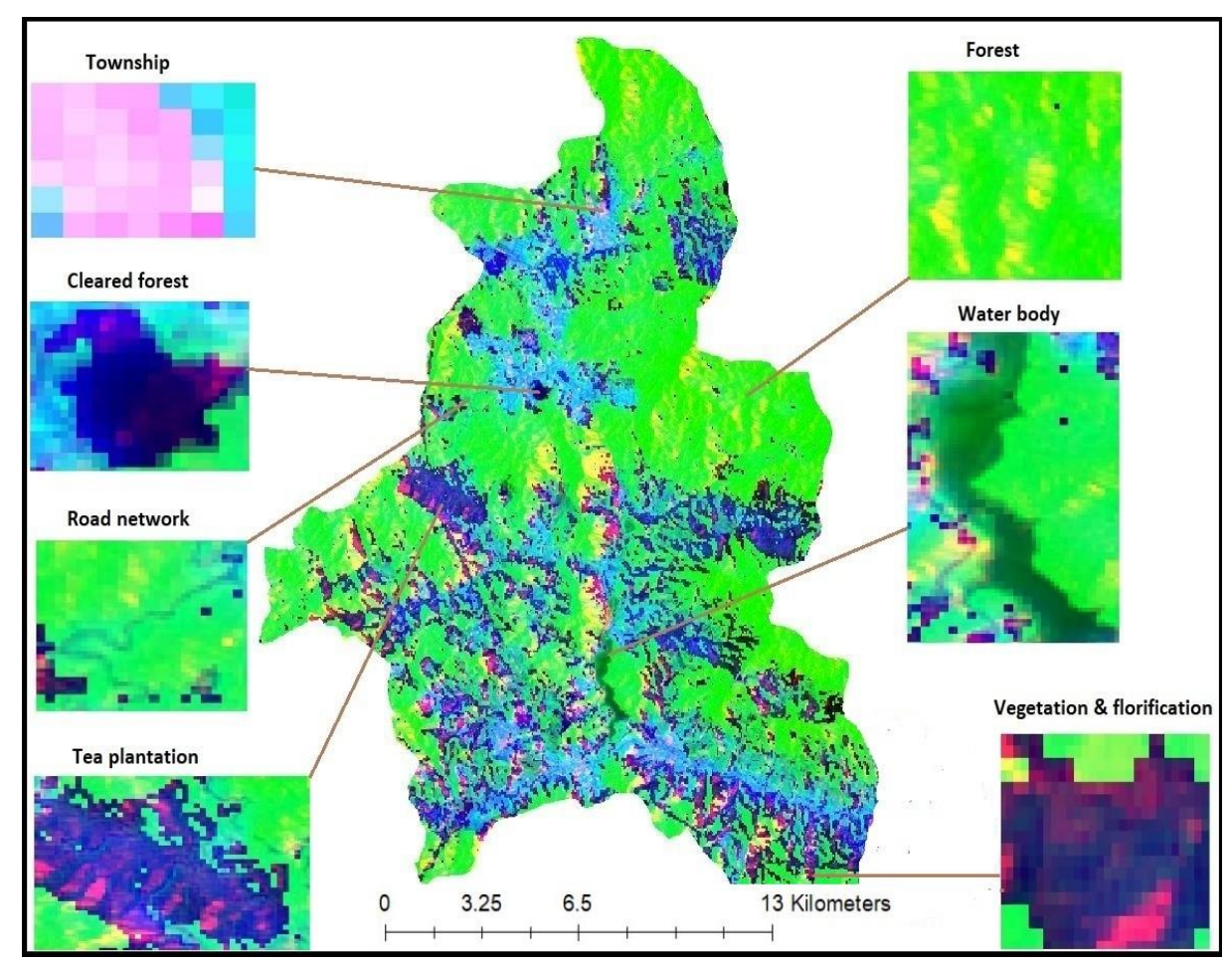

Figure 4. Different land cover's tones using combination model 
As a matter of fact, the land covers were extracted based on the ROIs extraction, where every land cover has its own reflection in the satellite imagery. If we do not extract the ROIs for one single land cover with a different reflection, it will remain unclassified. In this study, because of the different reflection in the satellite imagery, the tea plantation fields are separated from the vegetation coverage, spatially and statistically. Overall, a total number of 6 land covers were extracted for the study area (Table 3 and Fig. 5). Using ArcGIS and Microsoft Excel the area of extracted land covers were calculated and finalized. The vegetation and florification fields as well as the forest areas have the biggest area among all of $39.13176 \mathrm{~km}^{2}$ and $33.90341 \mathrm{~km}^{2}$, respectively. However, water body has the smallest area of only $0.364556 \mathrm{~km}^{2}$.

Table 3. The area of extracted land covers

\begin{tabular}{c|c|c}
\hline No & Name & Area $_{\mathbf{~ k m}}^{\mathbf{2}}$ \\
\hline $\mathbf{1}$ & Forest & 33.90341 \\
$\mathbf{2}$ & Water body & 0.364556 \\
$\mathbf{3}$ & Tea plantation & 3.024364 \\
$\mathbf{4}$ & Township & 4.139532 \\
$\mathbf{5}$ & Vegetation and florification & 39.13176 \\
$\mathbf{6}$ & Cleared forest & 0.436157 \\
\hline
\end{tabular}

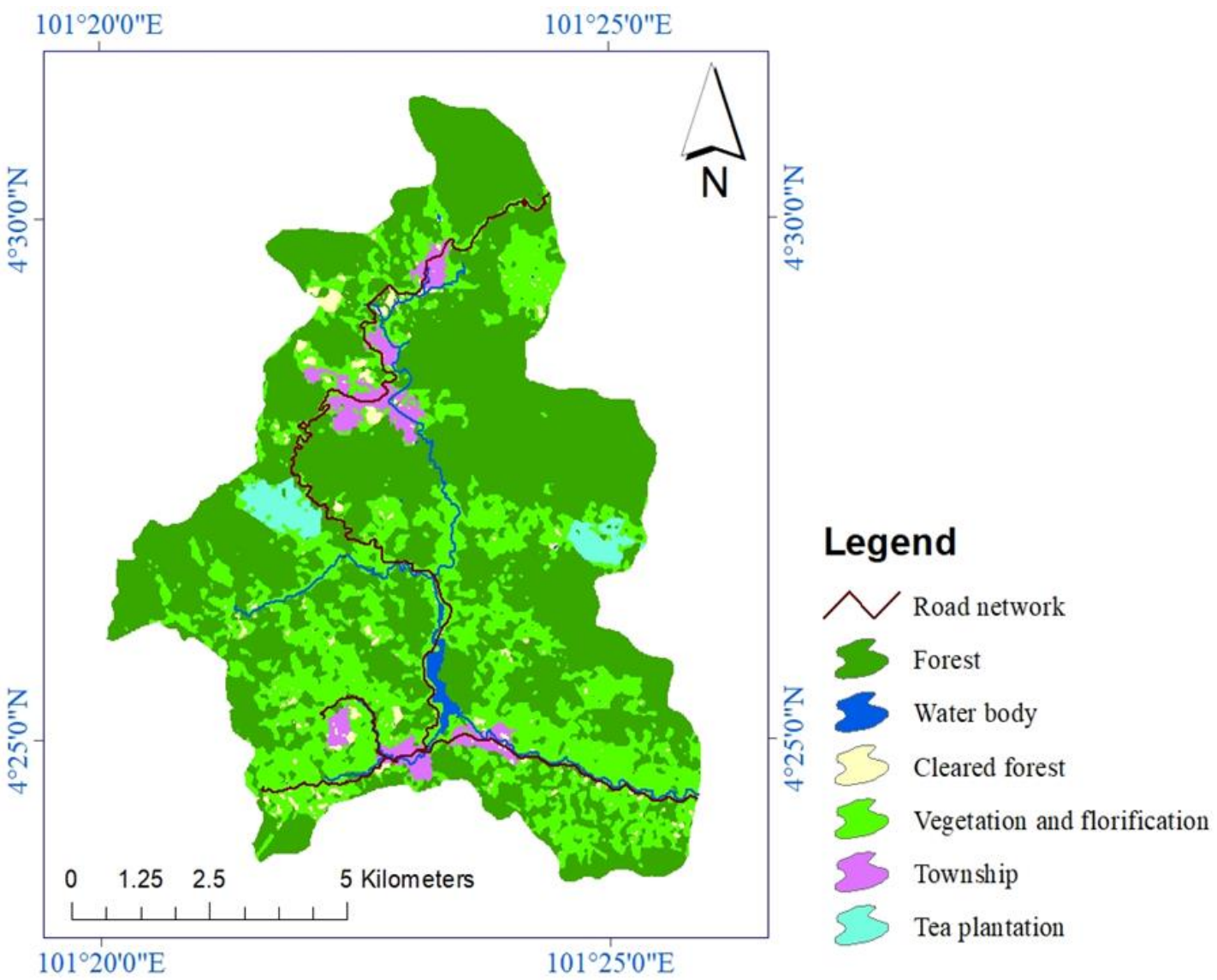

Figure 5. Land cover map of the study area 


\section{Validation}

Validation of land cover map is important to show the quality of used methods and techniques (Chen et al., 2017; Ma et al., 2017). Using a handheld Geographic Positioning System (GPS), a total number of 20 Ground Control Points (GCPs) were picked up for each land cover (Except the water body, where the Google Earth was employed for extracting GCPs for) by Ayub Mohammadi on Thursday 19 July, 2018 (Fig. 6). Because of the hilly situation of the Cameron Highlands, the GCPs were extracted near the main road and the accessible areas only. However, these GCPs were applied for validation purposes using the overall accuracy and Kappa statistic. Table 4 lists the result of the validation.

\section{Comparison of the combination model with a single model}

Using Enhanced Thematic Mapper plus (ETM+) satellite imagery for the date 06/09/2017 and Support Vector Machine (SVM) model, the land covers of the study area were extracted to compare with the combination model. Based on the results there are not too much differences between the two models statistically. The most considerable change has occurred inside the tea plantation area, where in the single model about $0.600 \mathrm{~km}^{2}$ was added to the tea fields. At the same time, roughly $1.80 \mathrm{~km}^{2}$ was decreased from the vegetation and florification areas (Table 5).

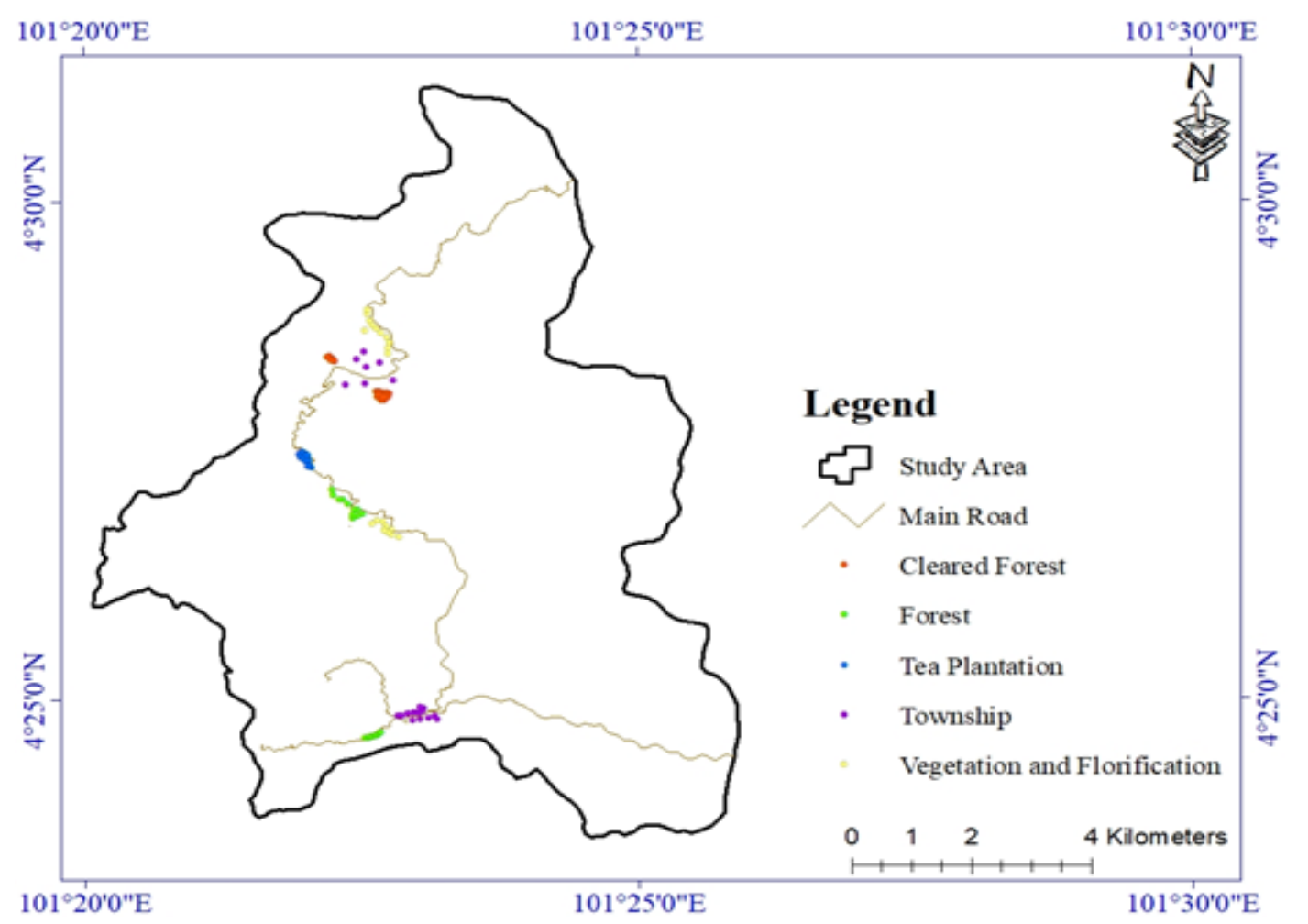

Figure 6. Shows the geographical positions of the extracted GPS points

Table 4. Highlights the confusion matrix for this study

\begin{tabular}{c|c}
\hline Overall accuracy & Kappa coefficient \\
\hline $98.1984 \%$ & 0.9579 \\
\hline
\end{tabular}


Table 5. Represents the area for extracted land covers from ETM+ and SVM model

\begin{tabular}{c|c|c}
\hline No. & Name & Area $\mathbf{k m}^{\mathbf{2}}$ \\
\hline $\mathbf{1}$ & Cleared forest & 0.429154 \\
$\mathbf{2}$ & Forest & 34.1433 \\
$\mathbf{3}$ & Tea plantation & 3.623 \\
$\mathbf{4}$ & Township & 4.63918 \\
$\mathbf{5}$ & Vegetation and florification & 38.0521 \\
$\mathbf{6}$ & Water body & 0.364556 \\
\hline
\end{tabular}

As a matter of fact, compared to the Google Earth images (Fig. 7), the combination model has shown the final map more realistic. In the output map of the single model the land covers are seen more unrealistic (especially for the vegetation and florification fields; Fig. 8).

\section{Conclusion}

Information about land covers is essential for environmental issues. Combination model refers to using the ability of two or more satellite imagery or even different algorithms, in which we can improve the spectral resolution of them to detect the land covers more precisely. In this study, a novel combination model of satellite imageries of Sentinel-1 and Landsat- 8 as well as the combination of different algorithms namely: maximum likelihood, minimum distance, support vector machine, spectral angle mapper, and artificial neural network were used for extracting land covers in a part of the Cameron Highlands, Pahang, Malaysia.

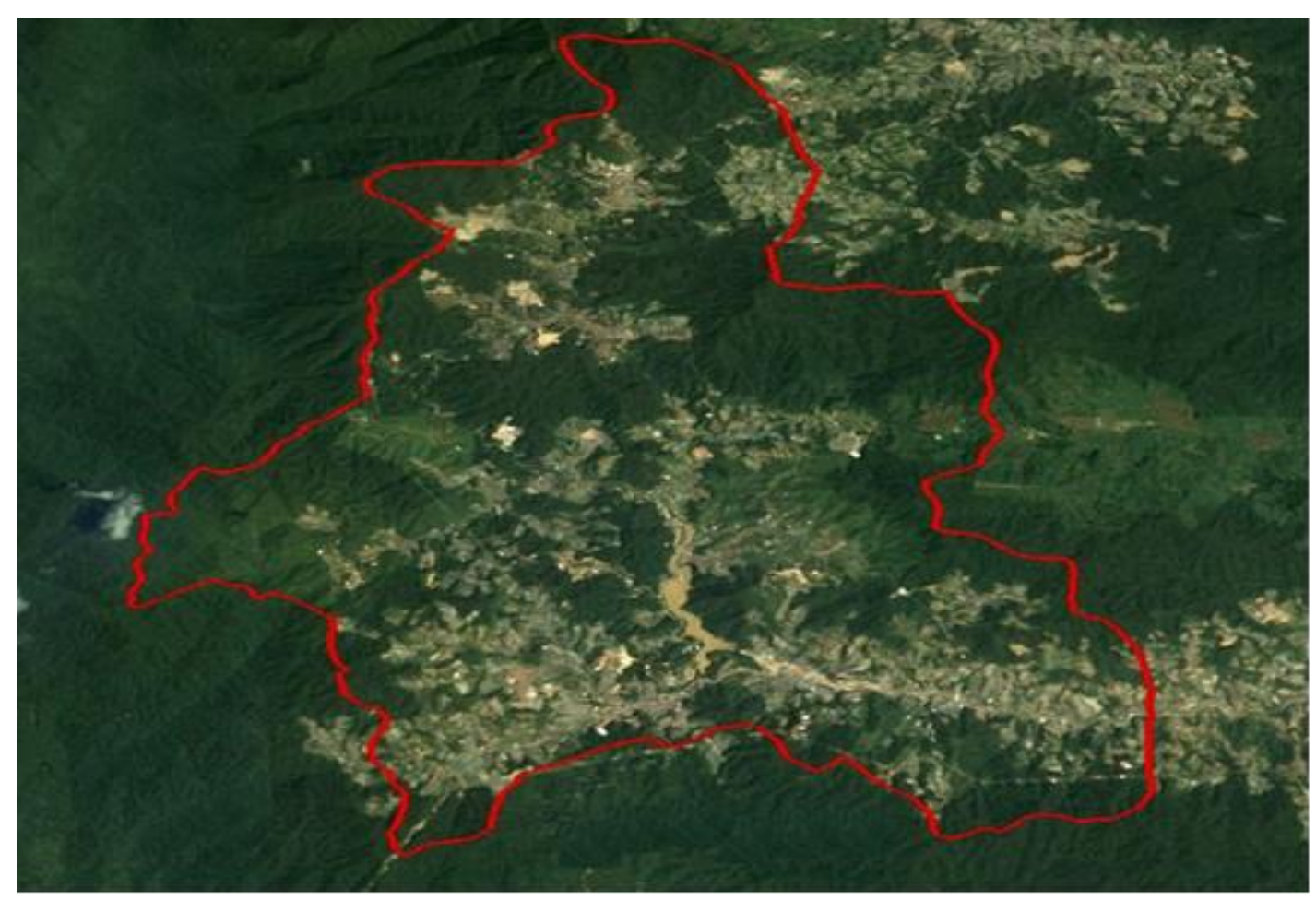

Figure 7. Shows the study area on the Google Earth image 


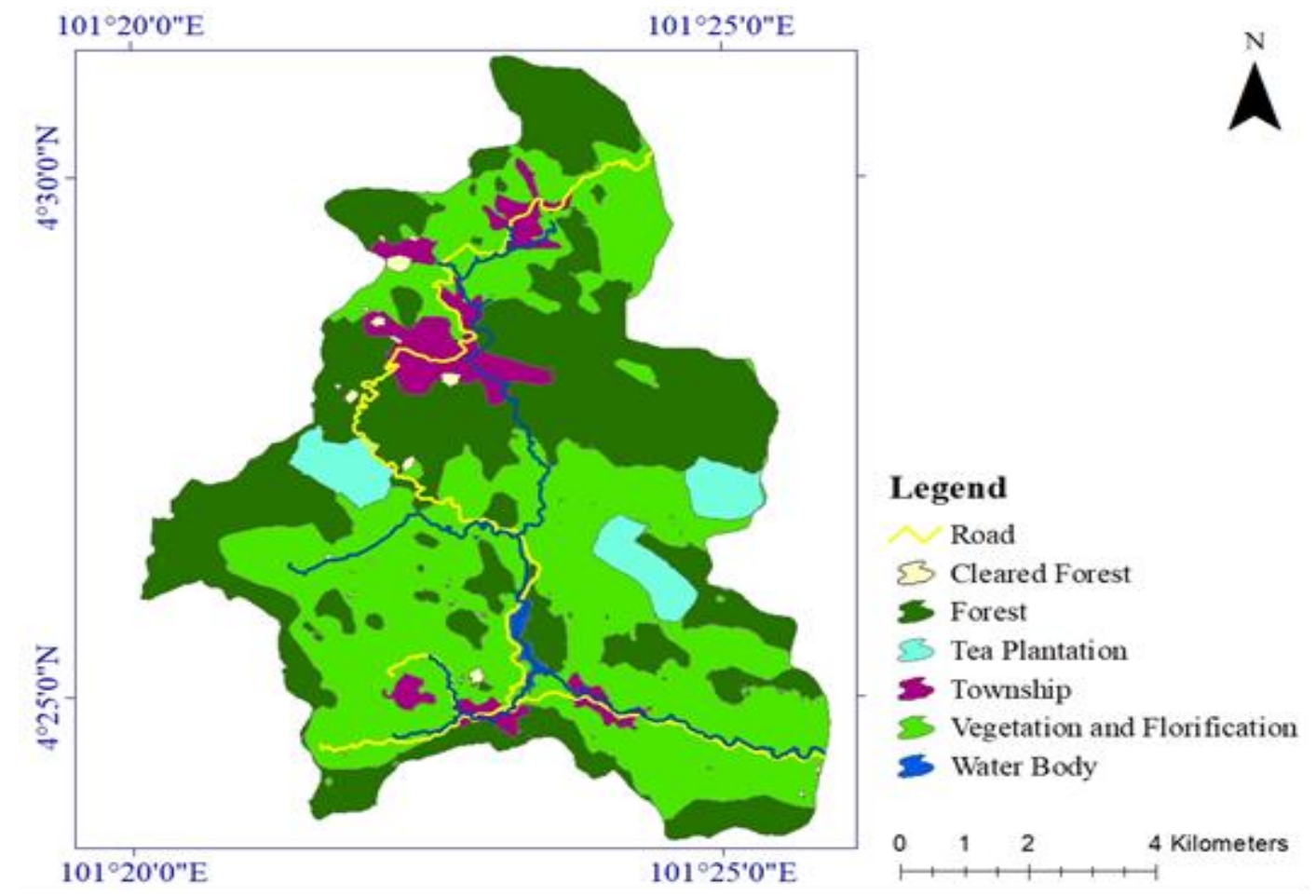

Figure 8. Illustrations of the extracted land covers using ETM+ and SVM model

However, a total number of 6 land covers were mapped, which using the Google earth and field survey all land covers were validated. Eventually, by a set of ground control points (GCPs), overall accuracy and Kappa statistic were measured of $98.1984 \%$ and 0.9579 , respectively. It is noticed that the outputs of this study have promising results for multi-temporal monitoring of land covers in the Cameron Highlands for long term analysis. The obtained results showed that dual Sentinel-1 (S1A, GRD, IW) and Landsat-8 Operational Land Imager (OLI) are suitable satellite imagers for rapid land cover extraction in the geographical situation with high similarity in land covers.

Acknowledgements. The authors wish to express their sincere thanks to Universiti Teknologi Malaysia (UTM) based on Research University Grant (Q.J130000.2527.17H84) for their financial supports.

\section{REFERENCES}

[1] Abtan, R. A., Al-Zuky, A. A., Al-Saleh, A. H., Mohamad, H. J. (2017): Movi-color target analysis based on using minimum distance classification. - Journal of College of Education 1: 45-60.

[2] Belward, A. S., Skøien, J. O. (2015): Who launched what, when and why; trends in global land-cover observation capacity from civilian earth observation satellites. - ISPRS Journal of Photogrammetry and Remote Sensing 103: 115-128.

[3] Chakraborty, S., Roy, M. (2018): A neural approach under transfer learning for domain adaptation in land-cover classification using two-level cluster mapping. - Applied Soft Computing 64: 508-525. 
[4] Chasmer, L., Hopkinson, C., Veness, T., Quinton, W., Baltzer, J. (2014): A decision-tree classification for low-lying complex land cover types within the zone of discontinuous permafrost. - Remote Sensing of Environment 143: 73-84.

[5] Chen, G. Y., Jia, Y. (2017): Integrating object boundary in super-resolution land-cover mapping. - IEEE Journal of Selected Topics in Applied Earth Observations and Remote Sensing 10: 219-230.

[6] Chen, J., Chen, J., Liao, A., Cao, X., Chen, L., Chen, X., He, C., Han, G., Peng, S., Lu, M. (2015): Global land cover mapping at $30 \mathrm{~m}$ resolution: A POK-based operational approach. - ISPRS Journal of Photogrammetry and Remote Sensing 103: 7-27.

[7] Gómez, C., White, J. C., Wulder, M. A. (2016): Optical remotely sensed time series data for land cover classification: A review. - ISPRS Journal of Photogrammetry and Remote Sensing 116: 55-72.

[8] Gong, P., Wang, J., Yu, L., Zhao, Y., Zhao, Y., Liang, L., Niu, Z., Huang, X., Fu, H., Liu, S. (2013): Finer resolution observation and monitoring of global land cover: First mapping results with Landsat TM and ETM+ data. - International Journal of Remote Sensing 34: 2607-2654.

[9] Griffiths, P., Van Der Linden, S., Kuemmerle, T., Hostert, P. (2013): A pixel-based Landsat compositing algorithm for large area land cover mapping. - IEEE Journal of Selected Topics in Applied Earth Observations and Remote Sensing 6: 2088-2101.

[10] Gu, B., Sheng, V. S. (2017): A robust regularization path algorithm for \$ \$nu \$-support vector classification. - IEEE Transactions on Neural Networks and Learning Systems 28: 1241-1248.

[11] Hasmadi, M., Pakhriazad, H., Shahrin, M. (2017): Evaluating supervised and unsupervised techniques for land cover mapping using remote sensing data. - GeografiaMalaysian Journal of Society and Space 5.

[12] Hua, L., Zhang, X., Chen, X., Yin, K., Tang, L. (2017): A feature-based approach of decision tree classification to map time series urban land use and land cover with Landsat $5 \mathrm{TM}$ and Landsat 8 OLI in a coastal city, China. - ISPRS International Journal of GeoInformation 6: 331 .

[13] Jebur, M. N., Pradhan, B., Tehrany, M. S. (2015): Using ALOS PALSAR derived highresolution DInSAR to detect slow-moving landslides in tropical forest: Cameron Highlands, Malaysia. - Geomatics, Natural Hazards and Risk 6: 741-759.

[14] Jensen, J. R., Lulla, K. (1987): Introductory digital image processing: a remote sensing perspective. - Geocarto International 2(1). https://doi.org/10.1080/10106048709354084.

[15] Khatami, R., Mountrakis, G., Stehman, S. V. (2016): A meta-analysis of remote sensing research on supervised pixel-based land-cover image classification processes: General guidelines for practitioners and future research. - Remote Sensing of Environment 177: 89-100.

[16] Kolesár, M. (2018): Minimum distance approach to inference with many instruments. Journal of Econometrics 204: 86-100.

[17] Kumar, P., Gupta, D. K., Mishra, V. N., Prasad, R. (2015): Comparison of support vector machine, artificial neural network, and spectral angle mapper algorithms for crop classification using LISS IV data. - International Journal of Remote Sensing 36: 16041617.

[18] Lamine, S., Petropoulos, G. P., Singh, S. K., Szabó, S., Bachari, N. E. I., Srivastava, P. K., Suman, S. (2018): Quantifying land use/land cover spatio-temporal landscape pattern dynamics from Hyperion using SVMs classifier and FRAGSTATS ${ }^{\circ}$. - Geocarto International 33: 862-878.

[19] Laurin, G. V., Liesenberg, V., Chen, Q., Guerriero, L., Del Frate, F., Bartolini, A., Coomes, D., Wilebore, B., Lindsell, J., Valentini, R. (2013): Optical and SAR sensor synergies for forest and land cover mapping in a tropical site in West Africa. International Journal of Applied Earth Observation and Geoinformation 21: 7-16. 
[20] Levin, N. (2016): Human factors explain the majority of MODIS-derived trends in vegetation cover in Israel: a densely populated country in the eastern Mediterranean. Regional Environmental Change 16: 1197-1211.

[21] Loveland, T. R., Reed, B. C., Brown, J. F., Ohlen, D. O., Zhu, Z., Yang, L., Merchant, J. W. (2000): Development of a global land cover characteristics database and IGBP DISCover from $1 \mathrm{~km}$ AVHRR data. - International Journal of Remote Sensing 21: 13031330.

[22] Lu, L., Di, L., Ye, Y. (2014): A decision-tree classifier for extracting transparent plasticmulched landcover from Landsat-5 TM images. - IEEE Journal of Selected Topics in Applied Earth Observations and Remote Sensing 7: 4548-4558.

[23] Ma, L., Li, M., Ma, X., Cheng, L., Du, P., Liu, Y. (2017): A review of supervised objectbased land-cover image classification. - ISPRS Journal of Photogrammetry and Remote Sensing 130: 277-293.

[24] Megahed, Y., Cabral, P., Silva, J., Caetano, M. (2015): Land cover mapping analysis and urban growth modelling using remote sensing techniques in greater Cairo region, Egypt. - ISPRS International Journal of Geo-Information 4: 1750-1769.

[25] Miettinen, J., Shi, C., Liew, S. C. (2016): Land cover distribution in the peatlands of Peninsular Malaysia, Sumatra and Borneo in 2015 with changes since 1990. - Global Ecology and Conservation 6: 67-78.

[26] Mohammadi, A., Shahabi, H., Bin Ahmad, B. (2018): Land-cover change detection in a part of Cameron Highlands, Malaysia using ETM+ satellite imagery and support vector machine (SVM) algorithm. - EnvironmentAsia 12 (in press).

[27] Moser, G., Serpico, S. B., Benediktsson, J. A. (2013): Land-cover mapping by Markov modeling of spatial-contextual information in very-high-resolution remote sensing images. - Proceedings of the IEEE 101: 631-651.

[28] Potin, P., Bargellini, P., Laur, H., Rosich, B., Schmuck, S. (2012): Sentinel-1 mission operations concept. - Geoscience and Remote Sensing Symposium (IGARSS) 2012 IEEE International 2012. IEEE 1745-1748.

[29] Poursanidis, D., Chrysoulakis, N., Mitraka, Z. (2015): Landsat 8 vs. Landsat 5: A comparison based on urban and peri-urban land cover mapping. - International Journal of Applied Earth Observation and Geoinformation 35: 259-269.

[30] Renza, D., Martinez, E., Molina, I. (2017): Unsupervised change detection in a particular vegetation land cover type using spectral angle mapper. - Advances in Space Research 59: 2019-2031.

[31] Richards, J. A., Richards, J. (1999): Remote Sensing Digital Image Analysis. - Springer, New York.

[32] Scott, G. J., England, M. R., Starms, W. A., Marcum, R. A., Davis, C. H. (2017): Training deep convolutional neural networks for land-cover classification of highresolution imagery. - IEEE Geoscience and Remote Sensing Letters 14: 549-553.

[33] Shahabi, H., Ahmad, B. B., Mokhtari, M. H., Zadeh, M. A. (2012): Detection of urban irregular development and green space destruction using normalized difference vegetation index (NDVI), principal component analysis (PCA) and post classification methods: a case study of Saqqez City. - International Journal of Physical Sciences 7: 2587-2595.

[34] Shao, Y., Lunetta, R. S., Wheeler, B., Iiames, J. S., Campbell, J. B. (2016): An evaluation of time-series smoothing algorithms for land-cover classifications using MODIS-NDVI multi-temporal data. - Remote Sensing of Environment 174: 258-265.

[35] Stamatakis, A. (2006): RAxML-VI-HPC: maximum likelihood-based phylogenetic analyses with thousands of taxa and mixed models. - Bioinformatics 22: 2688-2690.

[36] Stehman, S. V. (1997): Selecting and interpreting measures of thematic classification accuracy. - Remote sensing of Environment 62: 77-89.

[37] Sukawattanavijit, C., Chen, J., Zhang, H. (2017): GA-SVM algorithm for improving land-cover classification using SAR and optical remote sensing data. - IEEE Geoscience and Remote Sensing Letters 14: 284-288. 
[38] Tehrany, M. S., Pradhan, B., Jebuv, M. N. (2014): A comparative assessment between object and pixel-based classification approaches for land use/land cover mapping using SPOT 5 imagery. - Geocarto International 29: 351-369.

[39] Tien Bui, D., Shahabi, H., Shirzadi, A., Chapi, K., Alizadeh, M., Chen, W., Mohammadi, A., Ahmad, B., Panahi, M., Hong, H. (2018): Landslide detection and susceptibility mapping by AIRSAR data using support vector machine and index of entropy models in Cameron Highlands, Malaysia. - Remote Sensing 10: 1527.

[40] Walker, J., Blaschke, T. (2008): Object-based land-cover classification for the Phoenix metropolitan area: Optimization vs. transportability. - International Journal of Remote Sensing 29: 2021-2040.

[41] Yan, L., Roy, D. P. (2018): Large-area gap filling of landsat reflectance time series by spectral-angle-mapper based spatio-temporal similarity (SAMSTS). - Remote Sensing 10: 609.

[42] Yan, W. Y., Shaker, A., El-Ashmawy, N. (2015): Urban land cover classification using airborne LiDAR data: a review. - Remote Sensing of Environment 158: 295-310.

[43] Yoshida, T., Omatu, S. (1994): Neural network approach to land cover mapping. - IEEE Transactions on Geoscience and Remote Sensing 32: 1103-1109.

[44] Zhang, J., Foody, G. (2001): Fully-fuzzy supervised classification of sub-urban land cover from remotely sensed imagery: statistical and artificial neural network approaches. - International Journal of Remote Sensing 22: 615-628. 